\title{
Expanding the Breast Unit Accreditation Process to Ensure Standardization of Best Care for All Women Across Europe
}

\author{
Wolfgang Gatzemeier \\ European School of Oncology, Milan, Italy
}

Key Words

Breast cancer - Breast units, Accreditation . Quality assurance

\section{Summary}

Breast cancer is the most common cancer and the most frequent cause of cancer death in women throughout Europe. However, mortality from breast cancer is decreasing as a result of concerted action by all parties involved. It is now widely accepted that multidisciplinary teams form the basis for best practice in the management of breast cancer. Across Europe, women should have equity of access and the choice to select appropriate facilities for diagnosis and treatment and be sure they are receiving gold standard. European guidelines set up by the European Society of Mastology (EUSOMA) and the European Organization for the Research and Treatment of Cancer Breast Cancer Cooperative Group (EORTC-BCCG) to define the gold standard - entitled 'Requirements of a Breast Unit' - have been generally well received and have been influential in the introduction of the multidisciplinary approach in several countries. EUSOMA implemented a European accreditation process in order give guidance to patients and referring doctors to recognize which units meet the requirements and standards of best care.

\author{
Schlüsselwörter \\ Mammakarzinom - Brustzentren, Akkreditierung · \\ Qualitätssicherung
}

\section{Zusammenfassung}

Brustkrebs ist sowohl die häufigste Tumorerkrankung als auch die häufigste Todesursache bei malignen Erkrankungen der Frau in Europa. Durch verstärkte und verbesserte Zusammenarbeit von allen in Behandlung und Bekämpfung von Brustkrebs involvierten Personen konnte in den letzten Jahren eine Senkung der Sterblichkeitsrate erreicht werden. Es ist mittlerweile anerkannt, dass multidisziplinäre Teams die optimale Voraussetzung für die Früherkennung und bestmögliche Behandlung von Brustkrebs darstellen. Daher sollte das Ziel sein, allen Frauen in Europa in gleicher Weise die Möglichkeit zu gegeben, sich in einem Zentrum, welches über spezialisierte Einrichtungen und multidisziplinäre Teams verfügt, untersuchen und behandeln zu lassen. Die von der European Society of Mastology (EUSOMA) und der Breast Cancer Cooperative Group der European Organization for the Research and Treatment of Cancer (EORTC-BCCG) erarbeiteten Richtlinien zur Festlegung notwendiger Voraussetzungen für ein Brustzentrum - genannt 'Requirements of a Breast Unit' - wurden nicht nur sehr positiv aufgenommen, sondern hatten bereits einen merklichen Einfluss auf die Bildung multidisziplinärer Teams in verschiedenen europäischen Ländern. EUSOMA hat kürzlich ein europaübergreifendes Akkreditierungsverfahren für Brustzentren ins Leben gerufen. Zielsetzung ist sowohl Patientinnen als auch überweisenden Ärzten eine Orientierung zu geben, welche Einrichtungen über die notwendigen Voraussetzungen und Standards verfügen.

\begin{tabular}{ll}
\hline KARGER & ๑ 2006 S. Karger GmbH, Freiburg \\
$\begin{array}{l}\text { Fax +49 761 45207 14 } \\
\begin{array}{l}\text { E-mail Information@Karger.de } \\
\text { www.karger.com }\end{array}\end{array}$ & $\begin{array}{l}\text { Accessible online at: } \\
\text { www.karger.com/brc }\end{array}$ \\
&
\end{tabular}

Dr. Wolfgang Gatzemeier European School of Oncology Scientific Assistant to the Director Viale Beatrice d'Este, 37, 20122 Milan, Italy Tel. +39 02 85464-536, Fax -545 E-mailwgatzemei@aol.com 


\section{Background}

Breast cancer is the most common cancer and the most frequent cause of cancer death in women throughout Europe. However, mortality from breast cancer is decreasing as a result of concerted action by all parties involved, i.e. physicians, nurses, researchers, women at risk, patients, journalists, etc. Europe has a population of 500 million people more than half of which are women. At least 1 in 10 of these women will experience breast cancer. Therefore, this is a major public health priority.

\section{European Guidelines: Requirements of a Specialist Breast Unit}

In October 1998, the first European Breast Cancer Conference (EBCC) took place in Florence, Italy, jointly organized by the European Society of Mastology (EUSOMA), the European Organization for the Research and Treatment of Cancer Breast Cancer Cooperative Group (EORTC-BCCG), and EUROPA DONNA.

EUSOMA was established in 1986. It represents a group of medical professionals involved in all aspects of breast cancer. Its aims to harmonize the quality of breast cancer care throughout Europe by publishing management guidelines, fostering the establishment of breast units and developing training programs. For more details see www.eusoma.org.

EORTC-BCCG was created in 1962. It is a multidisciplinary group of surgeons, physicians and radiation therapists, and is focused on developing new treatments and research strategies for all types of breast cancer. For more details see www.eortc.be.

EUROPA DONNA, The European Breast Cancer Coalition, was founded in 1994. It aims to raise awareness of breast cancer and improve breast care services across Europe through advocacy and education. This non-profit organization represents the concerns of European women before local and national authorities as well as governments and the Institutes of the European Union. Each country has its own national EUROPA DONNA group called a forum. Currently, there are 39 member countries. The official website is $w w w$. europadonna.org.

'The Florence Statement' [1] established that all women across Europe should have access to fully equipped, dedicated breast units. As a consequence of the Florence statement, the 3 societies produced European guidelines defining the requirements for such units. These European guidelines stress the importance of multidisciplinarity (i.e. the collaboration between surgeons, radiologists, clinicians, pathologists, etc.) and multiprofessionality (i.e. the collaboration between doctors, nurses, psychologists, social workers, etc.). A group was formed in May 1999 in Leuven, Belgium, to draw up guidelines on these issues. The 'Requirements of a Breast Unit' rep- resents the opinion of EUSOMA and EORTC on the standards required for forming high-quality breast units across Europe [2]. The guidelines have been generally well received and have been influential in the introduction of the multidisciplinary approach in several countries. The Brussels Statement [3], following the second EBCC drew again attention to these guidelines and demanded that processes of accreditation of breast units be implemented and expanded. The importance of the establishment of multidisciplinary breast units was again stressed in the Hamburg Statement [4] which followed the fourth EBCC. Attention was drawn to the approval given to this by the European Parliament (Resolution Number A5-0159/2003) [5].

National governments should establish and accredit breast units in their countries in accordance with these guidelines and ensure that breast cancer diagnosis and care are carried out sufficiently in those units. All breast units should develop quality assurance programs and enter their data into a common European database. Furthermore, all breast units should collect data on incidence and mortality, which should also be pooled in a common European database. The statements following the fifth EBCC held in March 2006, in Nice, highlighted the issue of expanding accreditation of breast units on a European level. The objectives of the guidelines include: i) availability of high-quality specialist breast care for all women in Europe; ii) definition of standards for such a service; iii) recommendation that a means of accreditation and audit of breast units be established to make breast units recognizable to patients, practitioners and health authorities as being of high quality.

\section{The Challenge of Expanding the Breast Unit Accreditation Process Across Europe: EUSOMA's Commitment}

A difficulty faced by patients and referring doctors is how to recognize which units meet the requirements for being designated a specialist unit. Therefore, breast units should be accredited to ensure that they fulfil guideline requirements for standardization of best care. Accreditation guidelines for carrying this out should be developed not only by professionals, but also by patient advocacy groups. Women should have equity of access and the choice to select appropriate facilities for diagnosis and treatment and be sure they are receiving gold standard. Health matters remain the responsibility of individual governments, and it will be extremely difficult to bring about a universal process of accreditation, agreed and demanded as mandatory in all countries.

EUSOMA is the organization representing breast cancer specialists in all disciplines covering aspect of breast cancer from risk assessment and prevention, through diagnosis and treatment to the primary tumor, follow-up, treatment of recurrent and advanced disease, pathology, reconstruction, psychology 
and audit. EUSOMA has therefore implemented the process of Voluntary Accreditation, with the aim of assuring a highquality breast care service across Europe for the benefit of women in all member states [6]. If EUSOMA accreditation becomes widely recognized, it will become a de facto requirement for a breast unit professionally led and demanded by patients. Hospitals will be eager to claim that they have specialist breast units, and specialists will want to show that they work in recognized units.

In addition to breast specialists demanding specialized units, EUROPA DONNA has stated that working in specialist units will be of benefit to women. This organization will be influential in demanding that units ensure the upkeep of standards by seeking EUSOMA accreditation and in widely disseminating knowledge of which units are accredited.

EUREF (European Reference Organization for Quality Assured Breast Screening and Diagnostic Services) has produced the European Guidelines for Quality Assurance in Mammography Screening [7] which have been influential in member state government planning for screening, and has established a European program named 'Voluntary certification of high quality diagnostic breast imaging and breast screening services'. EUREF has already carried out certification visits to a number of units.

\section{EUSOMA Accreditation}

\section{The Structure}

A European Advisory Committee has been established to act in a liaison capacity in support of EUSOMA Accreditation and to inform women of the advantages of accredited units. The committee is composed of members of EUSOMA, EUREF and EUROPA DONNA as chairs, and a representative of the Federation of European Cancer Societies (FECS). A member of the European Parliament and a nominee of the European Commission will be invited to join the committee as observers.

Decision on the structure and methodology of EUSOMA Accreditation will be made only by the EUSOMA Executive Committee. The executive appoints the EUSOMA Accreditation Coordinator and the Accreditation Board. It is the responsibility of the Accreditation Board to decide on the accreditation status of each unit. The decision of the Board is final, and units will be informed as soon as the board has come to an agreement. The Accreditation Board comprises the following members: Chairman (accreditation co-ordinator), President (EUSOMA), Surgeon, Radiologist, Radiation Oncologist, Medical Oncologist, Radiologist with screening experience, Pathologist, Clinical Geneticist, Audit Adviser, Patient Advocate, Breast Care Nurse.

\section{Accreditation Process}

The process encompasses: 1) initial accreditation, 2) full accreditation and re-accreditation. The initial accreditation gives an individual unit the opportunity to meet the recommendations of the EUSOMA guidelines ('Requirements of a Breast Unit'). This refers to buildings, facilities, specialist team, protocols, service provision, database, and audit. The applying center must be situated within Europe. The initial accreditation is activated on electronic request by the unit. The application form is available on www.eusoma.org.

The unit will receive information on accreditation. After responding to this, the unit will be sent a questionnaire on their accommodation, specialist (core) team, working practices, non-core team members, equipment, staffing, protocols, audit, and research, set out to match the recommendations in the EUSOMA guidelines, and separate questionnaires on pathology and data collection/audit. A date for a visit is agreed with the unit, and an Accrediting Group from the Accreditation Board is chosen to visit. The group must include a surgeon (acting as clinician and therefore also as the visit coordinator), a diagnostic radiologist and a pathologist. An extra visitor from another discipline is from the field of patient support.

\section{Site Visit}

The site visit has the aim of meeting members of the unit team in all the core specialties, talking through the replies given on the questionnaires and on arrangements of the working week, ensuring that multidisciplinary work is carried out, and talking to some members of the associated services (non-core team).Full accreditation (and re-accreditation every 5 years) will depend on the Audit of Performance Indicators (such as pre-operative diagnosis rate, percentage of clear margins in breast-conserving therapy) and Outcome Measures (such as local recurrence rate after breast-conserving therapy). These are measured against the data collected in the years after the initial accreditation and transferred to the EUSOMA database.

\section{Conditions of Accreditation}

A unit must submit data (details of the patient age etc., diagnosis, primary operative and adjuvant therapies, tumor pathology and biology) and regular follow-up data to the EUSOMA Database for Primary Breast Cancer. Data will be anonymized to EUSOMA. The data accumulated is used for full and re-accreditation. In order to maintain accreditation, a unit must have at least 4 full members of EUSOMA (surgeon, pathologist, oncologist and radiologist). This is because the unit owns the data collected by EUSOMA for their re-accreditation and must therefore be represented by members. On receipt of the initial accreditation, the unit will become a partner in the EUSOMA Network of Accredited Units. If a unit no longer complies with these conditions (or) alters its structure or working practices so as to no longer satisfy the 
guidelines (or) fails full accreditation, accreditation will be withdrawn.

\section{EUSOMA Network of Accredited Units}

The list of Accredited Units will appear on the EUSOMA website together with a short description of the unit, its expertise and the services offered. EUSOMA started the accreditation process at the end of 2004.

In countries, such as Germany, where some of the desired expertise for breast cancer care (e.g. surgery, medical oncology) is provided predominantly by gynecologists, this fact is favorably taken into account, and accreditation can be granted as discussed above. In fact, in Germany there already are 9 accredited centers, and several others have started the process. One center in Switzerland has been approved and received initial accreditation. Partners in the EUSOMA network will own the collected data on the primary tumor (pathology, treatment and follow-up) submitted to the EUSOMA data- base to be used for full and re-accreditation. They will therefore be empowered to decide on which data may be analyzed collectively and used for research and the setting of standards. For this as well as for decisions on publications and research based on the collective data, the network members will elect a EUSOMA Network Subcommittee.

\section{Accreditation of Screening Units}

Screening units will be accredited separately from the breast unit by EUREF. EUREF has already defined its own processes for the certification of screening units (EUREF Certification Protocol) and has its own Certifying Groups. EUREF Certifying Groups will have a different composition from EUSOMA Accrediting Groups and include specialists from additional disciplines, e.g. a medical physicist, a diagnostic radiographer (technician) and an epidemiologist. Requests for EUREF certification should be sent directly to EUREF (www.euref.org)

\section{References}

1 Cataliotti L, Costa A, Daly PA, Fallowfield L, Freilich G, Holmberg L, Piccart M, van de Velde $\mathrm{CJH}$, Veronesi U: Florence statement on breast cancer, 1998. Forging the way ahead for more research on and better care in breast cancer. Eur J Cancer 1999;35:14-15.

2 EUSOMA: The requirements of a specialist breast unit. Eur J Cancer 2000;36:2288-2293.
3 Piccart M, Blamey R, Buchanan M, Cataliotti L, Costa A, Cuzick J, Freilich G, Jassem J, van de Velde CJH, Wilson R: Brussels Statement on Breast Cancer. Eur J Cancer 2001;37:1335-1337.

4 Jassem J, Buchanan M, Jänicke F, Baum M, Cataliotti L, Kyriakides S, Piccart M, Rutgers EJT, Costa A: The Hamburg statement: the partnership driving the European agenda on breast cancer. Eur J Cancer 2004;40:1810-1811.
5 Jöns K: European Parliament resolution on breast cancer in the European Union. 5 June 2003 (A5$0159 / 2003$ ).

6 www.eusoma.org/doc/EUSOMA\%20Accreditation \%20document\%2003.0206.pdf

7 European Guidelines for Quality Assurance in Mammography Screening, 3rd Edition. Luxembourg, Office for Official Publications of the European Communities, 2001 